\title{
Cross-reactivity among iodinated contrast agents: should we be concerned?
}

\author{
Adrian A. Schmid ${ }^{1}$, John N. Morelli ${ }^{2}$, Martin N. Hungerbühler ${ }^{3}$, Ingrid B. Boehm ${ }^{3} \wedge$ \\ ${ }^{1}$ Department of Orthopaedics and Traumatology, Spital Altstaetten, Altstaetten, Switzerland; ${ }^{2}$ Department of Radiology, St. John's Medical Center \\ Tulsa, OK, USA; ${ }^{3}$ Department of Diagnostic, Interventional, and Pediatric Radiology, Inselspital, University of Bern, Bern, Switzerland
}

Contributions: (I) Conception and design: All authors; (II) Administrative support: All authors; (III) Provision of study materials or patients: AA Schmid, IB Boehm; (IV) Collection and assembly of data: AA Schmid, MN Hungerbühler, IB Boehm; (V) Data analysis and interpretation: AA Schmid, IB Boehm; (VI) Manuscript writing: All authors; (VII) Final approval of manuscript: All authors.

Correspondence to: Dr. Ingrid B. Boehm, MD. Department of Diagnostic, Interventional, and Pediatric Radiology, Inselspital, University of Bern, Freiburgstrasse 10, CH-3010 Bern, Switzerland. Email: ingrid.boehm@insel.ch.

\begin{abstract}
Background: Although several papers deal with "cross-reactivity" in patients with iodinated contrast medium (ICM) hypersensitivity reactions (HSRs), there is no in-depth knowledge of this phenomenon. To define ICM-groups as potential reaction partners and to identify any potential clinical relevance in patients with ICM-HSRs.

Methods: The literature database PubMed was searched for eligible papers dealing with ICM-allergy and "cross-reactivity". The data presented by the papers was analyzed and individual patient data was extracted for re-evaluation based on a definition for both 'polyvalent reactivity' and 'cross-reactivity' as well as for chemical structure-dependent ICM-groups.

Results: Twenty-five original papers (with $n=340$ extracted patients) formed the study population. Incidences of polyvalent reactivity were non-significantly higher than incidences of cross-reactivity (both range from $0 \%$ to $100 \%$ ). Crossover evaluation in reaction pairings (culprit ICM A with ICM B versus culprit ICM B with ICM A) showed concordance of only 30\%. Data support rather non-cross-reactivity (individual reaction pattern) than cross-reactivity constellations.
\end{abstract}

Conclusions: The obtained results favour an individual reaction pattern, rather than a reactivity driven by chemical structures and so-called cross-reactivity.

Keywords: Cross-reactivity; drug provocation test (DPT); hypersensitivity reaction (HSR); immediate reaction (IR); iodinated contrast medium (ICM); non-immediate reaction (NIR); polyvalent reactions; risk stratification

Submitted Dec 01, 2020. Accepted for publication Apr 14, 2021.

doi: 10.21037/qims-20-1325

View this article at: http://dx.doi.org/10.21037/qims-20-1325

\section{Introduction}

Currently, iodinated contrast media (ICM) are most common used drugs in radiology. Although exact data are unknown, an estimated number of several hundred million doses worldwide per year are administered with increasing frequency (1). This large number of ICMdoses makes hypersensitivity reactions (HSRs) induced by ICMs a challenge in radiology, despite its low incidence of $0.004-3.0 \%(2,3)$. Upon its occurrence, immediate reactions (IRs) and non-immediate reactions (NIRs) should

^ ORCID: 0000-0002-2382-6636. 
be treated adequately. Following these reactions, patients with a history of a previous ICM-HSR are at higher risk to experience another adverse reaction following reexposure to contrast materials. Therefore, these patients require special prophylaxis (e.g., anti-allergic prophylaxis, antihistamines with or without glucocorticosteroids) before they can receive another ICM.

Selection of an alternative ICM in an individual patient is another option, especially in those with a history of moderate reactions (in cases with severe reaction both ICM switch and premedication could be meaningful) $(4,5)$. In the latter subgroup, a skin test can be helpful in the decision making process. ICMs producing a positive skin test should be avoided, but those exhibiting a negative skin test remain candidates for suitable subsequent ICMenhanced imaging. Sometimes, allergy testing [intradermal testing (IDT) as well as drug provocation tests (DPTs)] not only shows a reaction against the culprit compound but also against one or more other compounds. The literature calls this phenomenon "cross-reactivity" (6-17) or unspecific, irritative reactions (18). Although several papers deal with ICM 'cross-reactivity' (6-17), currently, the phenomenon is largely not understood and its clinical relevance is uncertain. This is particularly the central question of whether or not cross-reactivity should be considered when radiologists choose a non-culprit ICM in at-risk patients without a formal allergy workup. In this context, we tried to answer questions such as, which phenomenon "cross-reactivity" or individual reaction pattern plays the major role in clinical routine?" Therefore, the goal of the present study is to analyse systematically the phenomenon of 'cross-reactivity', and its clinical relevance.

\section{Methods}

\section{Definition of cross-reactivity and polyvalent reactivity}

Herein we focused on ICMs only, and used a definition that has been published (19). Briefly, skin tests displaying only one positive result are called monovalent reactivity. Skin tests showing two or more positive reactions across all ICM compounds are called polyvalent reactivity (formerly called "cross-reactivity"). Cross-reactivity (CR) is defined as multiple (two or more) positive test reaction within defined chemical ICM-groups (19). As mentioned previously, the following available and FDA-approved ICM compounds were grouped according to similarities of their chemical structures (19): iopentol, ioversol, iomeprol, iohexol, iodixanol, iosimenol, iopromide, iobitridol, iosarcol, iotrolan, amidotrizoate, ioxithalamate, and ioxaglate.

We need the differentiation between polyvalent reactivity and cross-reactivity, because the cross-reactivity does not depend on the iodine atom. In other words, the alleged "iodine allergy" does not exist $(1,5)$. Moreover, the differentiation between polyvalent and cross-reactivity is one focus of our study.

We define as opposite to patients with cross-reactivity such with non-cross-reactivity or individual reaction pattern. The latter group is composed of patients with both monovalent reactivity, and polyvalent reactivity that does not fit into the cross-reactivity group.

\section{Literature search criteria}

Two investigators independently searched the online database PubMed from January 1995 until December 2019. The keywords "cross-reactivity", "cross sensitivity", "skin testing", and "contrast media" were utilized in various combinations to find eligible articles. In addition, reference lists of relevant articles as well as the authors' personal literature database were also scrutinized for other papers eligible for inclusion [papers from other sources (Figure 1)]. Full text research articles, short communications, case series (with more than three cases), and letters to the editor available online were included. Review articles, in vitro studies, studies focusing on gadolinium-based contrast agents, and animal studies were excluded. The search was limited to articles available in English.

\section{Data extraction and study design}

Eligible publications were searched according to metaanalysis criteria, but a formal meta-analysis was not performed. Two investigators independently extracted relevant data from each article. Discrepancies were resolved in consensus. The data extracted included the following information: name of the first author, year of publication, number of analyzed patients, number of patients showing polyvalent reactivity/cross-reactivity, type of hypersensitivity (IR or NIR), number of positive test reactions, and DPTs if performed.

Next, single published patients and their test results were re-evaluated. We documented the following data: age, sex, culprit ICM, tested ICMs and the results, and the type of HRS (IR or NIR). Patients with a minimum of one positive skin test reaction were extracted and pooled. 


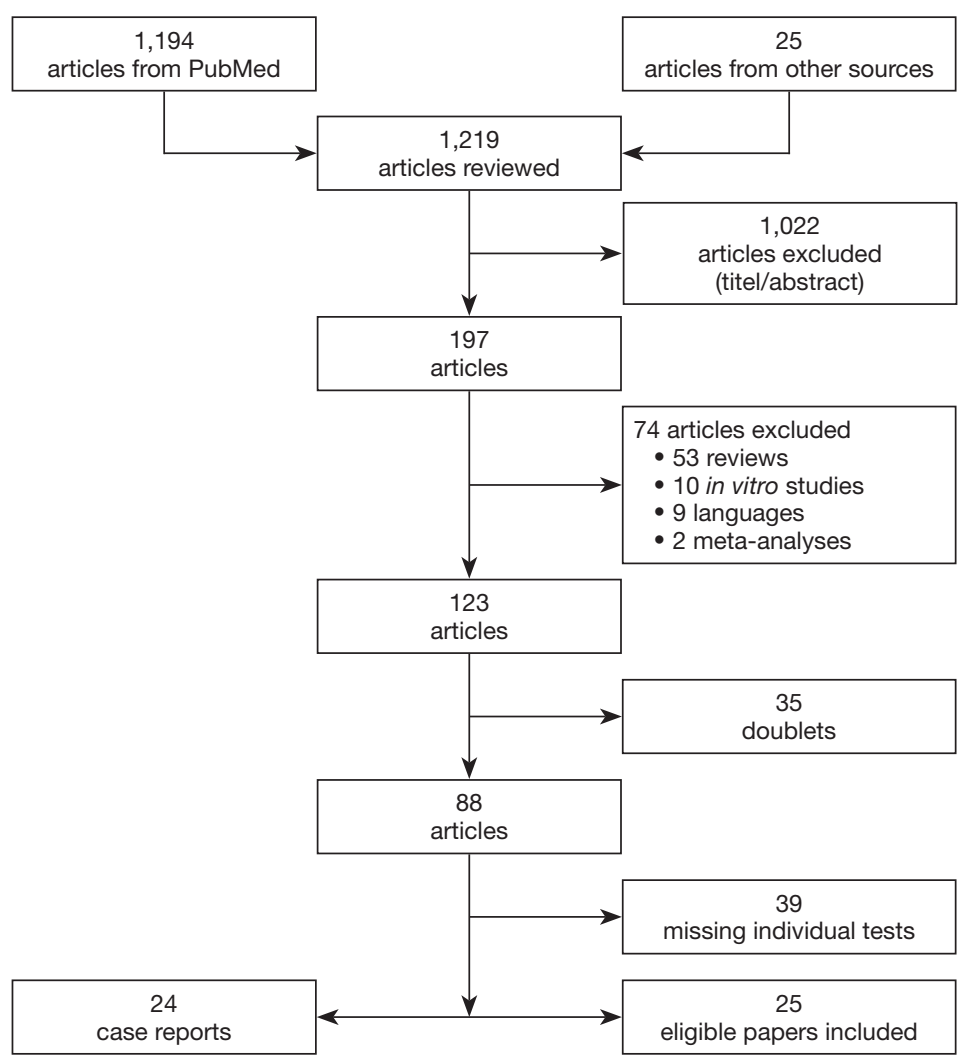

Figure 1 Number of detected publications after PubMed database screening, and exclusion of non-relevant papers.

\section{Statistical analysis}

Demographic data, clinical characteristics, and test results were analyzed using descriptive statistics. The frequency of cross-reactivity/polyvalent reactions was calculated as the quotient of number of patients with multiple positive test reactions and the number of patients with positive test result.

The correlation coefficient (Spearman's rho) was calculated to determine the correlation of number of tested ICMs and number of positive reactions.

For categorical data, Chi-squared or Fisher's exact test was utilized. Continuous variables were expressed by mean and standard deviations (mean $\pm \mathrm{SD}$ ), and compared by MannWhitney $U$ test or the Student's T-test. Odds ratios (ORs) and their $95 \%$ confidence intervals $(95 \% \mathrm{CI})$ were calculated, and comparisons between different groups were made.

Sensitivity, specificity, positive predictive value (PPV), and negative predictive value (NPV), were analysed through the comparison of the chemical ICM-groupings (see also under 'Chemical ICM-groups' in the results section). We do not aim to analyse these parameters with respect to the gold standard, ICM re-exposure under radiological diagnostic conditions or by application the contrast medium in the context of a DPT.

We categorized the frequency of cross-reactivity/ polyvalent reactivity into not likely $(<25 \%)$, less likely $(25-$ $50 \%)$, likely (51-75\%), and very likely (>75\%).

$\mathrm{P}$ values of less than 0.05 were considered statistically significant. STATA software version 12.1 Inc., Chicago, IL, USA was utilized for statistical analysis.

\section{Results}

\section{Study overview}

Twenty-five articles published in 2001-2019 met the abovementioned inclusion criteria. We excluded 1,194 of 1,219 identified publications, because their content did not fit into the study design or essential data were missing (Figure 1). A total pooled cohort of 2,444 patients presented in 25 papers comprised the study population. In 619 patients (25.3\%), we documented positive skin test reactions. Nine studies focused on subjects with IR, ten on patients with NIR, and six studies on both IR and NIR (Table 1). 


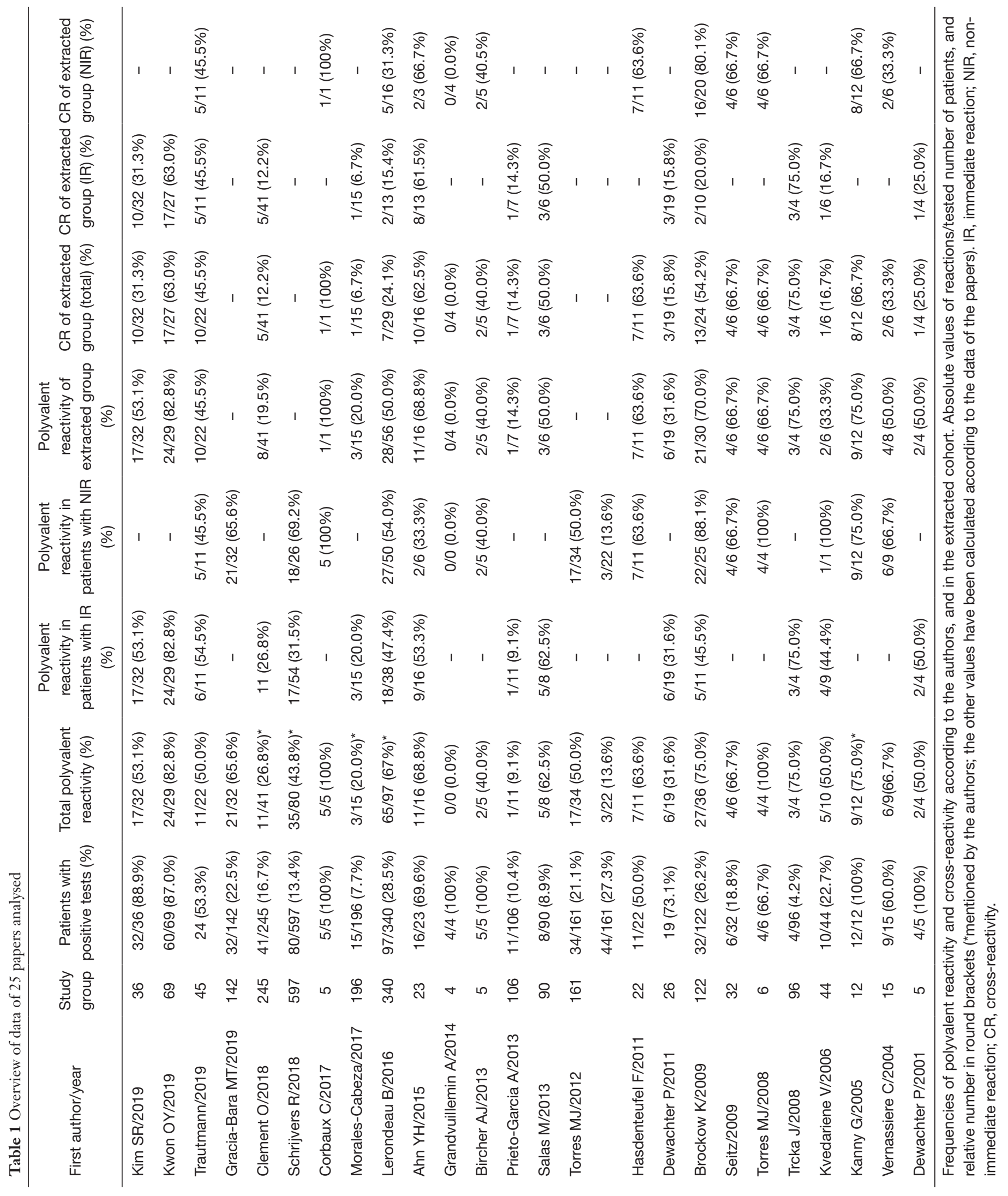




\begin{tabular}{|c|c|c|c|c|c|c|c|c|c|c|c|c|c|c|}
\hline $\begin{array}{l}\text { Cross-reac- } \\
\text { ting com- } \\
\text { pound }\end{array}$ & $\begin{array}{l}\overline{0} \\
\text { O } \\
\text { D } \\
\text { 으 } \\
\text { 으 }\end{array}$ & $\begin{array}{l}\overline{0} \\
\stackrel{\Phi}{\mathbb{D}} \\
\text { 心D } \\
\underline{0}\end{array}$ & $\begin{array}{l}\overline{0} \\
\overline{3} \\
\text { 응 } \\
\text { 응 }\end{array}$ & $\begin{array}{l}\overline{0} \\
\text { ○े } \\
\text { 㐅े } \\
\underline{0}\end{array}$ & 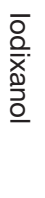 & $\begin{array}{l}\bar{D} \\
\underline{\underline{W}} \\
\overline{\mathbf{D}} \\
\underline{\mathbb{D}} \\
\underline{0}\end{array}$ & $\begin{array}{l}\overline{0} \\
\frac{0}{0} \\
\frac{0}{3} \\
\frac{3}{0}\end{array}$ & 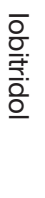 & $\begin{array}{l}\overline{0} \\
\text { 음 } \\
\overline{3} \\
\overline{\overline{0}} \\
\text { 으 }\end{array}$ & $\begin{array}{l}\overline{0} \\
\text { Dू } \\
\bar{ָ} \\
\underline{0}\end{array}$ & $\begin{array}{l}\bar{o} \\
\frac{\bar{t}}{2} \\
\frac{0}{\partial}\end{array}$ & 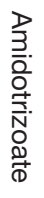 & 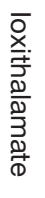 & 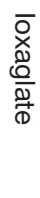 \\
\hline lopentol & 0 & $x$ & $x$ & $x$ & $x$ & $x$ & $x$ & & & & & & & \\
\hline loversol & $x$ & 0 & $x$ & $x$ & $x$ & $x$ & $x$ & & & & & & & \\
\hline lomeprol & $x$ & $x$ & $\mathrm{O}$ & $x$ & $x$ & $x$ & $x$ & & & & & & & \\
\hline lohexol & $\mathrm{x}$ & $\mathrm{x}$ & $x$ & 0 & $x$ & $x$ & $x$ & & & & & & & \\
\hline lodixanol & $x$ & $x$ & $x$ & $x$ & 0 & $x$ & $x$ & & & & & & & \\
\hline Iosimenol & $x$ & $x$ & $x$ & $x$ & $x$ & 0 & $x$ & & & & & & & \\
\hline lopromide & $x$ & $x$ & $x$ & $x$ & $x$ & $x$ & 0 & $x$ & & & & & & \\
\hline lobitridol & & & & & & & $x$ & 0 & & & & & & \\
\hline lopamidol & & & & & & & & & 0 & & & & & \\
\hline losarcol & & & & & & & & & & 0 & & & & \\
\hline lotrolan & & & & & & & & & & & o & & & \\
\hline Amidotrizoate & & & & & & & & & & & & 0 & & \\
\hline loxithalamate & & & & & & & & & & & & & 0 & \\
\hline loxaglate & & & & & & & & & & & & & & 0 \\
\hline
\end{tabular}

Figure 2 Expected cross-reactivity. Among available/known ICMs (iodinated contrast media) due to their chemical structure expected crossreactivity is shown within black open rectangles. ICM, iodinated contrast medium.

\section{Chemical ICM-groups}

Based on their similar chemical side chains, eight ICMgroups were defined (Figure 2), including one large group consisting of seven ICMs, one small group consisting of two ICMs, and six groups consisting of only one ICM (19). The large group shares the $\mathrm{N}$-(2,3-dihydroxypropyl)carbamoyl chemical moiety, and the small one the $\mathrm{N}-(2,3-$ dihydroxypropyl)-N-methyl-carbamoyl moiety (Figure 3). The remaining six ICMs do not share chemical groups with other contrast agents (Figure 2).

Figure 4 shows the cross-reactivity classification of correct/false positive and negative reactions with respect to the culprits' ICM grouping.

We hypothesized that ICM cross-reactions should preferentially occur within the defined groups. Inside the groups $582(48.3 \%)$ and outside $246(17.7 \%)$ of all skin tests were positive $[\mathrm{P}<0.0001$; risk ratio 2.7 (95\% CI: 2.4-3.1)] (Figure 5). The relative risk of an ICM cross-reaction within a chemically defined group was 2.7 times greater than between agents in other groups.

\section{Re-evaluation of extracted patient data}

Allergic subjects who were tested positively against ICMs and in whom individual skin test results were available from the literature were extracted. Of 619 reported patients with positive skin test reactions (Table 1), re-evaluation was possible in a subgroup of 340 patients. We excluded 279 patients because of missing individual data or because the culprit ICM was unknown.

Patients had a mean age of 55 years (range, 7-93 years) and consisted of 85 men and 122 women (gender of 133 patients was unknown). In 331 patients, a single ICM was the culprit for the reaction. In nine patients, two culprit ICM were identified. Two hundred eighteen (64.1\%) patients had a history of an IR, 121 (35.6\%) of a NIR, and one patient experienced a bi-phasic reaction with both IR and NIR.

The culprit-ICMs were positive tested in 289 cases (82.8\%). Within the IR subgroup, 433 (27.5\%) positive test results were obtained in 1,575 tested ICMs. The NIR subgroup had $363(37.0 \%)$ positive test results, and 981 ICMs were tested. 

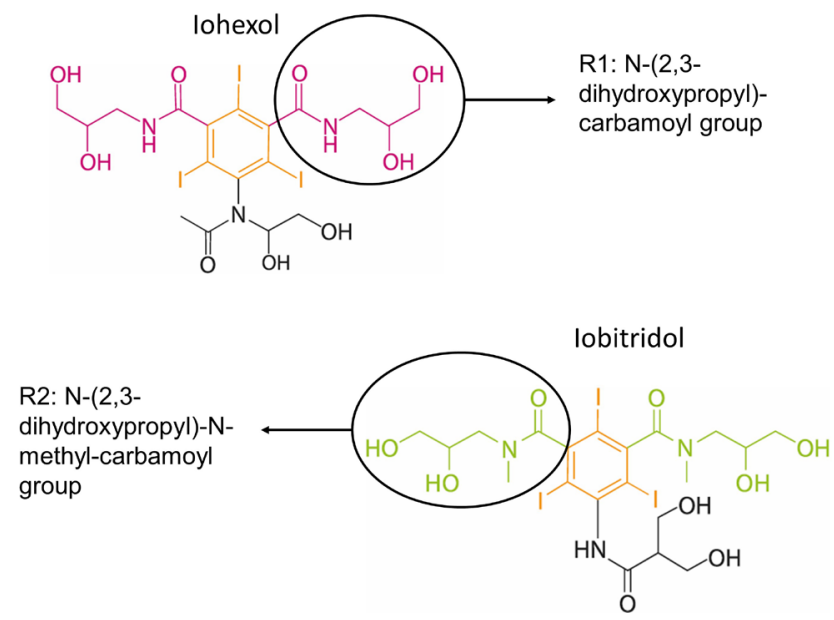

Figure 3 Chemical structure of iohexol (above), and iobitridol (below) and the relevant chemical groups that share other ICMs too. ICM, iodinated contrast medium.

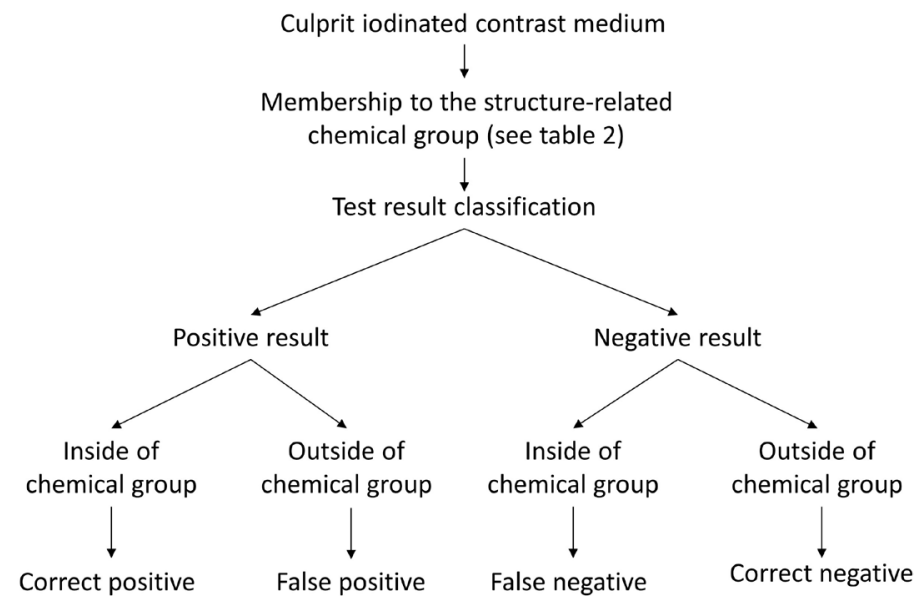

Figure 4 Overview of the decision making and classification of "correct positive", "false positive", "false negative" and "correct negative" cross-reactivity test reactions according to the structure-related chemical grouping of the ICMs (see Figure 2). ICM, iodinated contrast medium.

\section{Correlation of tested ICMs}

Of the 2,547 tested ICMs, 795 positive reactions (sensitivity 0.31 ) could be detected. In order to find a possible dependency of the number of positive test reactions upon the number of tested ICMs we correlated these data (Spearmans rho), and found no statistical significant correlation (Figure S1).

\section{Sensitivity and specificity}

Based upon the chemical grouping in Figure 2, we identified
580 positive and 622 negative test reactions within chemical groups, as well as 1,165 negative test results outside of the chemical groups, and positive reactions outside of chemical group could be found in 253 tests (Figure 6). These results led to sensitivity of 0.48 , specificity 0.82 , PPV 0.70 , and NPV 0.65; OR 4.22 (95\% CI: 3.5-5.0).

\section{Frequency/incidence/risk}

The incidence of cross-reactivity and polyvalent reactivity ranges from $0 \%$ to $100 \%$ (Table 1 ). The mean is $51.2 \%$, and the median $50 \%$ for polyvalent reactions, and $42.3 \%$ and 


\begin{tabular}{|c|c|c|c|c|c|c|c|c|c|c|c|c|}
\hline Culprit ICM & \multicolumn{9}{|c|}{ Frequency of positive test reactions against } & loxaglate & loxithalamate & lotrolan \\
\hline lohexol (43) & $\begin{array}{l}39 / 43 \\
(0.91)\end{array}$ & $\begin{array}{l}11 / 24 \\
(0.46)\end{array}$ & $\begin{array}{c}6 / 8 \\
(0.75)\end{array}$ & $\begin{array}{l}19 / 29 \\
(0.66)\end{array}$ & $\begin{array}{l}20 / 41 \\
(0.49)\end{array}$ & $\begin{array}{l}19 / 35 \\
(0.54)\end{array}$ & $\begin{array}{l}6 / 38 \\
(0.16)\end{array}$ & $\begin{array}{l}14 / 37 \\
(0.38)\end{array}$ & $\begin{array}{l}0 / 16 \\
(0.0)\end{array}$ & $\begin{array}{l}3 / 23 \\
(0.13)\end{array}$ & $\begin{array}{l}4 / 20 \\
(0.2)\end{array}$ & $\begin{array}{c}0 / 2 \\
(0.00)\end{array}$ \\
\hline lomeprol (74) & $\begin{array}{l}14 / 57 \\
(0.25)\end{array}$ & $\begin{array}{l}64 / 73 \\
(0.88)\end{array}$ & $\begin{array}{c}6 / 14 \\
(0.43)\end{array}$ & $\begin{array}{l}17 / 59 \\
(0.29)\end{array}$ & $\begin{array}{l}18 / 63 \\
(0.29)\end{array}$ & $\begin{array}{l}14 / 58 \\
(0.24)\end{array}$ & $\begin{array}{l}6 / 59 \\
(0.10)\end{array}$ & $\begin{array}{l}15 / 54 \\
(0.28)\end{array}$ & $\begin{array}{l}1 / 37 \\
(0.03)\end{array}$ & $\begin{array}{l}12 / 50 \\
(0.24)\end{array}$ & $\begin{array}{l}3 / 41 \\
(0.07)\end{array}$ & $\begin{array}{l}3 / 11 \\
(0.27)\end{array}$ \\
\hline loversol (27) & $\begin{array}{l}8 / 23 \\
(0.35)\end{array}$ & $\begin{array}{l}9 / 24 \\
(0.38)\end{array}$ & --- & $\begin{array}{l}20 / 27 \\
(0.74)\end{array}$ & $\begin{array}{l}1 / 19 \\
(0.05)\end{array}$ & $\begin{array}{c}5 / 9 \\
(0.56)\end{array}$ & $\begin{array}{l}4 / 23 \\
(0.17)\end{array}$ & $\begin{array}{l}4 / 25 \\
(0.16)\end{array}$ & $\begin{array}{l}1 / 12 \\
(0.08)\end{array}$ & $\begin{array}{l}2 / 16 \\
(0.13)\end{array}$ & $\begin{array}{l}1 / 12 \\
(0.08)\end{array}$ & $\begin{array}{c}0 / 1 \\
(0.00)\end{array}$ \\
\hline lodixanol (67) & $\begin{array}{l}27 / 64 \\
(0.42)\end{array}$ & $\begin{array}{l}13 / 63 \\
(0.21)\end{array}$ & $\begin{array}{l}7 / 20 \\
(0.35)\end{array}$ & $\begin{array}{l}14 / 55 \\
(0.25)\end{array}$ & $\begin{array}{l}47 / 67 \\
(0.70)\end{array}$ & $\begin{array}{l}5 / 26 \\
(0.19)\end{array}$ & $\begin{array}{l}14 / 53 \\
(0.26)\end{array}$ & $\begin{array}{l}16 / 59 \\
(0.27)\end{array}$ & $\begin{array}{l}0 / 33 \\
(0.0)\end{array}$ & $\begin{array}{l}11 / 47 \\
(0.23)\end{array}$ & $\begin{array}{l}8 / 35 \\
(0.23)\end{array}$ & $\begin{array}{c}0 / 2 \\
(0.00)\end{array}$ \\
\hline lobitridol (35) & $\begin{array}{l}9 / 34 \\
(0.26)\end{array}$ & $\begin{array}{l}3 / 31 \\
(0.10)\end{array}$ & $\begin{array}{c}4 / 9 \\
(0.44)\end{array}$ & $\begin{array}{l}4 / 28 \\
(0.14)\end{array}$ & $\begin{array}{l}6 / 32 \\
(0.19)\end{array}$ & $\begin{array}{l}6 / 24 \\
(0.25)\end{array}$ & $\begin{array}{l}30 / 35 \\
(0.86)\end{array}$ & $\begin{array}{l}6 / 24 \\
(0.25)\end{array}$ & $\begin{array}{l}2 / 23 \\
(0.09)\end{array}$ & $\begin{array}{l}7 / 31 \\
(0.23)\end{array}$ & $\begin{array}{l}5 / 30 \\
(0.17)\end{array}$ & $\begin{array}{c}1 / 4 \\
(0.25)\end{array}$ \\
\hline Iopamidol (37) & $\begin{array}{l}10 / 30 \\
(0.33)\end{array}$ & $\begin{array}{l}3 / 22 \\
(0.14)\end{array}$ & $\begin{array}{l}0 / 4 \\
(0.0)\end{array}$ & $\begin{array}{l}4 / 23 \\
(0.17)\end{array}$ & $\begin{array}{l}4 / 30 \\
(0.13)\end{array}$ & $\begin{array}{l}11 / 26 \\
(0.42)\end{array}$ & $\begin{array}{l}7 / 32 \\
(0.22)\end{array}$ & $\begin{array}{l}32 / 37 \\
(0.86)\end{array}$ & $\begin{array}{l}0 / 4 \\
(0.0)\end{array}$ & $\begin{array}{l}0 / 11 \\
(0.0)\end{array}$ & $\begin{array}{l}0 / 3 \\
(0.0)\end{array}$ & $\begin{array}{c}0 / 2 \\
(0.00)\end{array}$ \\
\hline $\begin{array}{l}\text { Amidotrizoate } \\
\text { (2) }\end{array}$ & $\begin{array}{l}0 / 1 \\
(0.0)\end{array}$ & $\begin{array}{l}0 / 1 \\
(0.0)\end{array}$ & --- & $\begin{array}{l}0 / 1 \\
(0.0)\end{array}$ & $\begin{array}{l}0 / 2 \\
(0.0)\end{array}$ & $\begin{array}{l}0 / 1 \\
(0.0)\end{array}$ & $\begin{array}{l}0 / 2 \\
(0.0)\end{array}$ & $\begin{array}{l}0 / 1 \\
(0.0)\end{array}$ & $\begin{array}{l}2 / 2 \\
(1.0)\end{array}$ & $\begin{array}{c}0 / 2 \\
(0.0)\end{array}$ & $\begin{array}{c}0 / 2 \\
(0.0)\end{array}$ & - \\
\hline loxaglate (25) & $\begin{array}{l}0 / 22 \\
(0.0)\end{array}$ & $\begin{array}{l}2 / 24 \\
(0.08)\end{array}$ & $\begin{array}{l}0 / 7 \\
(0.0)\end{array}$ & $\begin{array}{l}2 / 21 \\
(0.10)\end{array}$ & $\begin{array}{l}1 / 18 \\
(0.06)\end{array}$ & $\begin{array}{l}2 / 20 \\
(0.1)\end{array}$ & $\begin{array}{l}2 / 22 \\
(0.09)\end{array}$ & $\begin{array}{l}3 / 12 \\
(0.25)\end{array}$ & $\begin{array}{l}1 / 18 \\
(0.06)\end{array}$ & $\begin{array}{l}23 / 25 \\
(0.92)\end{array}$ & $\begin{array}{l}5 / 25 \\
(0.20)\end{array}$ & $\begin{array}{c}0 / 1 \\
(0.00)\end{array}$ \\
\hline $\begin{array}{l}\text { loxithalamate } \\
\text { (2) }\end{array}$ & $\begin{array}{c}1 / 2 \\
(0.50)\end{array}$ & --- & $\begin{array}{c}1 / 1 \\
(1.0)\end{array}$ & --- & $\begin{array}{c}1 / 1 \\
(1.0)\end{array}$ & --- & $\begin{array}{l}0 / 1 \\
(0.0)\end{array}$ & $\begin{array}{c}0 / 2 \\
(0.0)\end{array}$ & $\begin{array}{c}1 / 2 \\
(0.50)\end{array}$ & $\begin{array}{c}0 / 2 \\
(0.0)\end{array}$ & $\begin{array}{c}1 / 2 \\
(0.50)\end{array}$ & $\begin{array}{c}1 / 1 \\
(1.00)\end{array}$ \\
\hline
\end{tabular}

Figure 5 Frequencies of positive test reactions. Pairings and frequencies of positive test reactions against single ICMs (iodinated contrast media) with respect to the culprit ICM (iodinated contrast medium). Values in bold = result is lower (grey background: values should be $>0.5$ ) or higher (white background: values should be $<0.5$ ) than expected. ICM, iodinated contrast medium.

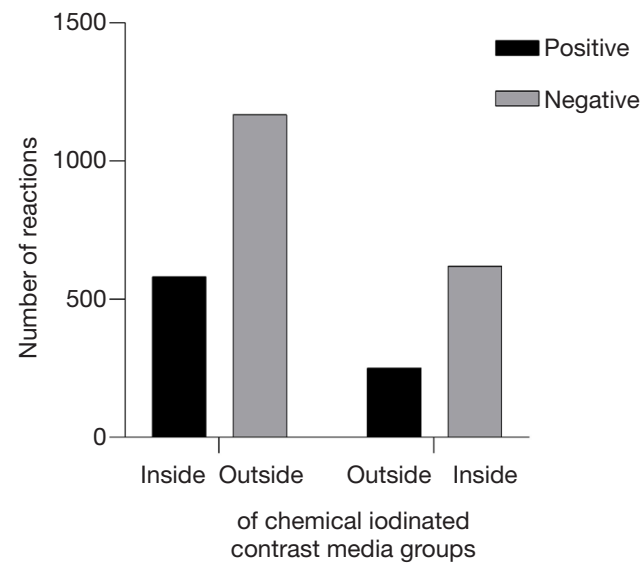

Figure 6 Intradermal test results in the re-evaluated patient group.

\section{$42.5 \%$ for cross-reactivity.}

Overall, the incidences of polyvalent reactivity are higher than incidences of cross-reactivity. The difference was statistically not significant.

Cross-reactivity was present in $7 \%$ to $75 \%$ (mean $32.4 \%$ ) IR-patients of the extracted patient group and in $0 \%$ to $100 \%$ (mean $55.1 \%)$ NIR-subjects $(\mathrm{P}<0.01)$.

According to the authors, 619 patients had positive reactions, and $262(42.3 \%)$ had polyvalent reactions. Considering all tested ICMs of the re-evaluated group, polyvalent reactions were present in 178 (52.4\%) cases. Following exclusion of positive reactions outside of chemical groups, 122 (35.8\%) patients (127 reactions) remained with cross-reactivity $(\mathrm{P}<0.0001)$ (Table 2).

The comparison of the two subgroups cross-reactivity and non-cross-reactivity shows a dominance of the latter (Table 2). While IRs are more common in the non-cross- 
Table 2 Comparison between patients with and without cross-reactivity

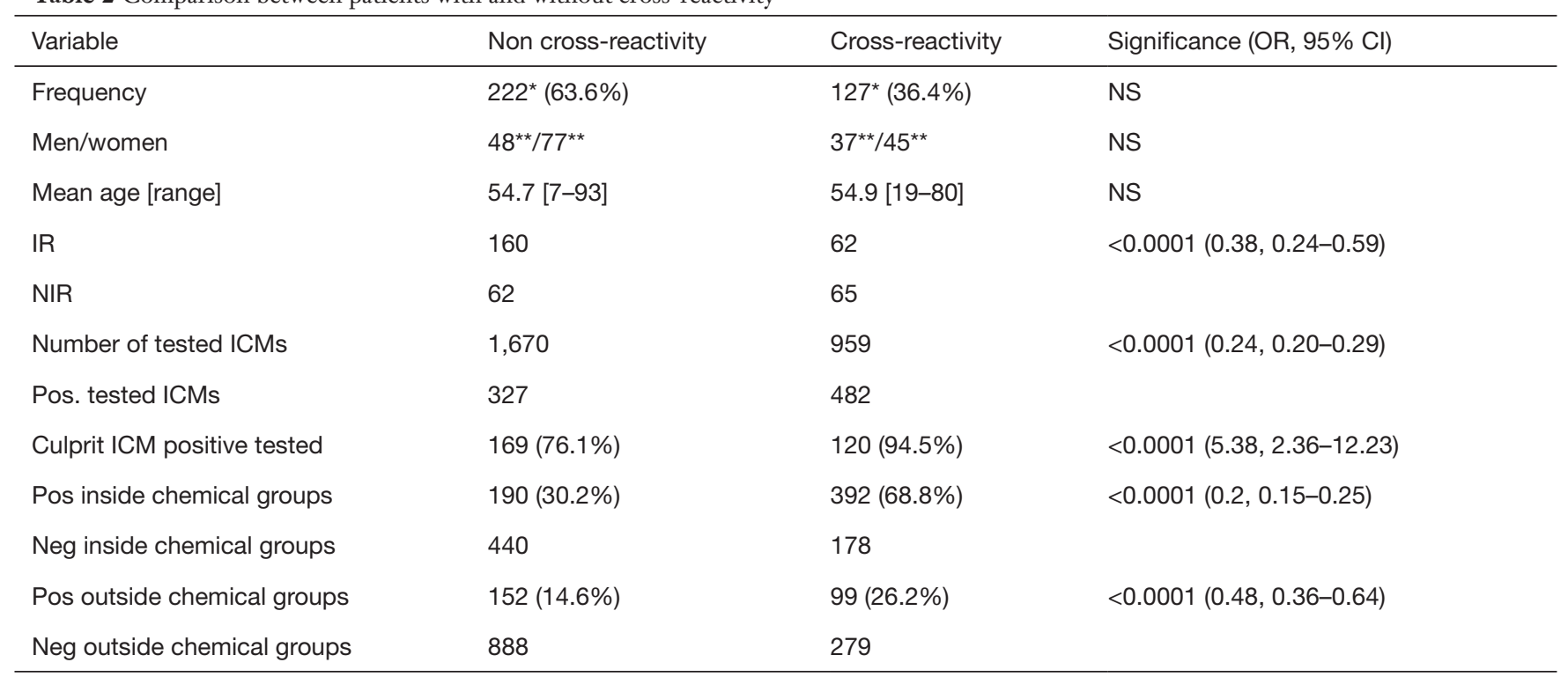

Comparison between patients showing cross-reactivity according to Figure 2 with those showing non cross-reactivity. *Sum $>340$, because nine pats had two culprit ICMs; **exclusion of unknown gender. OR, odds ratio; 95\% Cl, 95\% confidence interval; IR, immediate reaction; NIR, non-immediate reaction; ICMs, iodinated contrast media; pos, positive; neg, negative.

reactivity subgroup, NIRs dominate in the cross-reactivity subgroup $(\mathrm{P}<0.0001)$.

\section{Crossover evaluation}

Based on Figure 5, frequencies of positive reactions within of two reactivity-pairings (special culprit ICM and another ICM), and vice versa were built to test the hypothesis that the chemical structure could be responsible for the obtained test frequencies (crossover evaluation). For example, we compared the frequency of the reaction constellation iohexol (culprit)-iomeprol (reaction partner) with the frequency of iomeprol (culprit)-iohexol (reaction partner) (Figure 5). Since it should not matter which ICM is the culprit and which is the reaction partner, we defined equal or concordant reaction frequencies to be within $5 \%$ and differences in frequencies $\geq 6 \%$ to be not equal. We assessed 55 reaction-pairings. Five were excluded because of missing test results. Of the remaining 50 reactionpairings, concordance was established in $15(30 \%)$ and not established in $35(70 \%)$ cases.

\section{Subgroup analyses}

In the next step, we analysed subgroups with identical culprit ICM (Figure 7). Thereby, it became clear that the culprit ICM induced the highest incidence of positive test results. The obtained relative frequencies vary from $50 \%$ to 100\% (mean 84\%).

The single results are presented in Figure 5. The greatest chemical group contains 36 single results. The constellation ioversol (as culprit ICM) and iopentol (as tested compound) is missing. In 23 single results the obtained frequency is lower than expected (bold numbers in Figure 5), and 12 other single results show the expected frequencies. The small chemical group with iopromide and iobitridol shows twice too low values and twice expected frequencies. Three of the remaining four other chemical groups with only one ICM inside showed frequencies in expected dimensions, and once a too low value (Figure 5).

\section{Results of ICM challenge tests}

We identified 200 challenge tests in the literature. According to Figure 2 and the chemical group classification scheme, twenty tests were positive inside the chemical groups, 39 tests were negative inside the chemical groups, 129 tests were negative outside the chemical groups, and 12 tests were positive outside the chemical groups (Figure 8). Consequently, with respect to the chemical group classification the following parameters were calculated, the sensitivity of 0.34 (95\% CI: $0.2241-0.4749)$, specificity 0.91 
lohexol

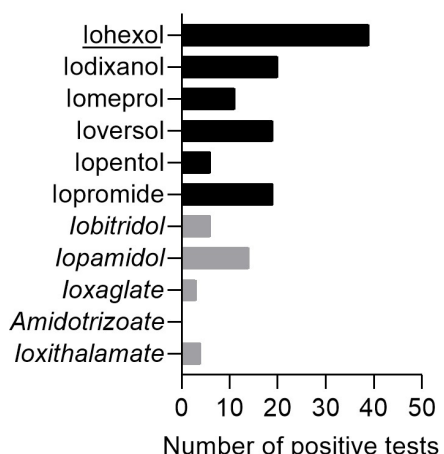

Iopromide

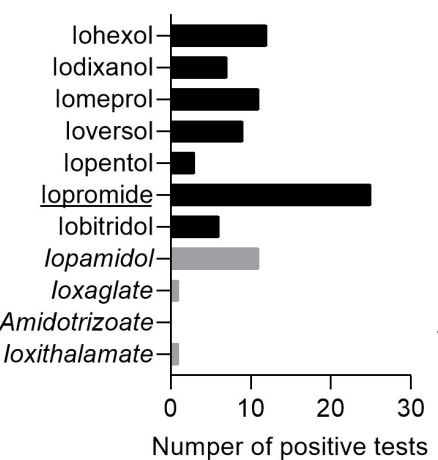

lodixanol

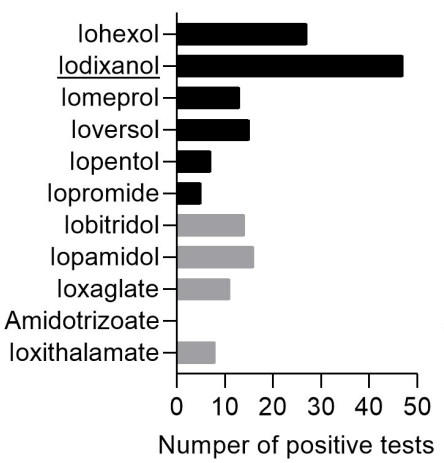

lobitridol

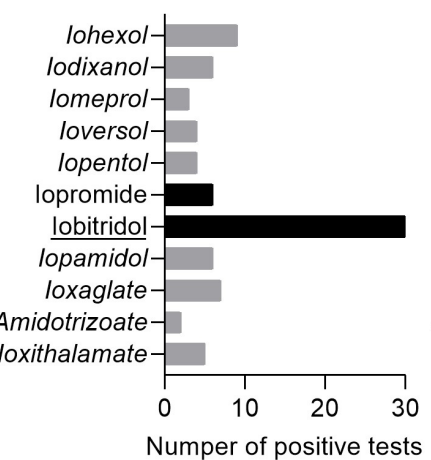

lomeprol

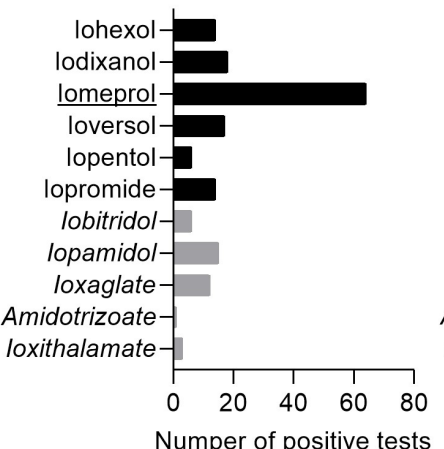

Iopamidol

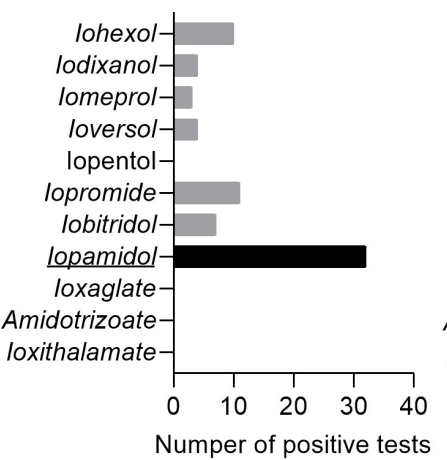

loversol

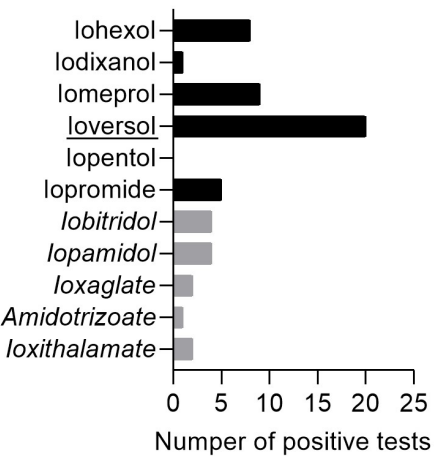

loxaglate

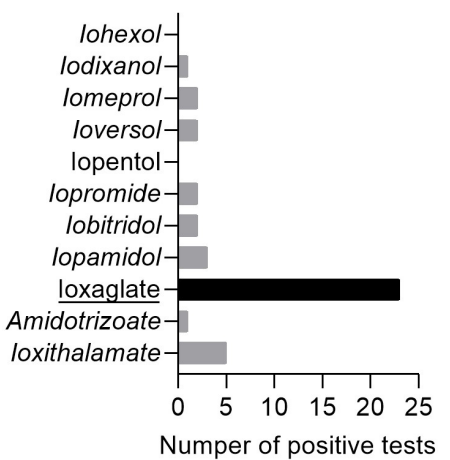

Figure 7 Subgroups with identical culprit ICM (mentioned on top), and the incidences of cross-reactivity (expected reactions = black), and non-cross-reactivity (not expected reactions = grey) in skin tests. ICM, iodinated contrast medium.

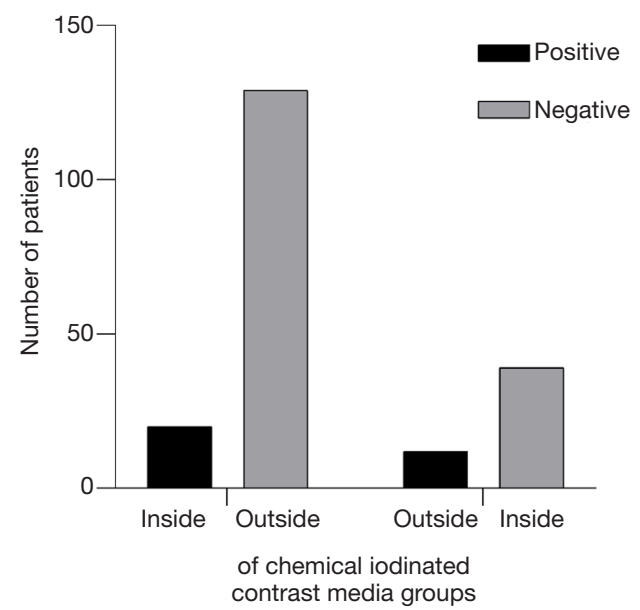

Figure 8 Results of drug provocation tests (DPTs) in the reevaluated patient group.
(95\% CI: 0.8529-0.9533) $(\mathrm{P}<0.0001)$, OR 0.18 (95\% CI: 0.08-0.40), NPV 0.77 (95\% CI: 0.6953-0.8279), and PPV 0.625 (95\% CI: $0.4375-0.7834)$.

\section{Final evaluation}

Based on the above presented results, in a final multi-step process, the likelihood of cross-reactivity or an individual reaction pattern (non-cross-reactivity) was evaluated.

(I) The correlation of tested ICMs with positive skin test reactions was assessed to determine whether ICM-test reactions are specific or unspecific (Figure S1). A correlation factor of $\mathrm{r}=0.05357(\mathrm{P}>0.05)$ was calculated for the extracted and re-evaluated patient group. These results indicate that the number of positive test results does not depend upon the number of tested ICMs. Therefore, rather a specific than nonspecific reactivity can be assumed.

(II) Next, the frequencies/incidences of both polyvalent 
and cross-reactivity in the 25 clinical studies $(8,10$ $16,20-36$ ) ranging from $0 \%$ to $100 \%$ (Table 1 ), also suggest an individual reaction pattern (noncross-reactivity) rather than a chemical structure dependent reactivity (cross-reactivity).

(III) Frequencies based on Figure 2 (cross-reactivity) are usually lower than frequencies among all available ICMs (polyvalent reactivity). The lower the difference between these values the more likely the cross-reactivity. We found in nine studies equal values for cross-reactivity and polyvalent, and in 12 studies different values (Table 1).

(IV) Cross-over evaluation with identical reactivity-pairings in different roles (culprit ICM and another nonculprit ICM) showed in 30\% concordance, and in 70\% discordance (Figure 5). This low value also supports the assumption of an individual reaction pattern.

(V) Although not significant, the phenomenon crossreactivity is less common than non-cross-reactivity (36.4\% versus $63.6 \%$ ) (Table 2).

These results favour an individual reaction pattern, rather than a reactivity driven by chemical groups and socalled cross-reactivity.

\section{Discussion}

This study for the first time presents in-depth analyses of the 'cross-reactivity' phenomenon in patients with ICMallergy. Available literature provides a correct definition of chemical groups responsible for 'cross-reactivity' (19), but lacks a critical analysis of its clinical relevance. Especially, the question as to whether 'cross-reactivity' or 'non-crossreactivity' plays the major role is of great clinical impact, because in patients at risk a well-tolerated non-culprit ICM even without an allergy test result should be found. This prompted us to analyse existing data from the literature to understand better the phenomenon called 'cross-reactivity'.

\section{Terminology}

The correct use of terms is helpful in understanding the 'cross-reactivity' phenomenon. Most papers dealing with this topic utilized no definition of the term, and referred to it synonymously with the term polyvalent positive reactions $(3,8,26,30)$. However, this incorrectly implicates the iodine atom as being responsible for the reactivity, thereby resuscitating the old, incorrect concept of the "iodine allergy" $(1,5)$.

\section{Definition of chemical groups of ICMs}

Although cross-reactivity depends on similar chemical groups, a clear definition is missing in most papers of the literature. The grouping described by Lerondeau $e t a l$. is confusing and it is uncertain how it was constructed (10).

This original paper for the first time used and identifies chemical groups (19) of the available ICMs as a basis for potential cross-reactivity (Figures 2,3). One large group consisting of iopentol, ioversol, iomeprol, iohexol, iodixanol, iosimenol, iopromide, and another smaller group consisting of iopromide and iobitridol cover the most clinically used ICMs. The difference between members of the two larger groups is minimal, comprising of a methyl group only (Figure 3). The remaining six ICMs iopamidol, iosarcol, iotrolan, amidotrizoate, ioxithalamate, and ioxaglate are soloists. This means they are not readily grouped together based on common chemical structures (Figure 2).

The proposed grouping appears to have some validity, because we found a statistically significant greater proportion of positive reactions within than outside of these groups (see Results under 'Chemical groups' and in Figure 5). On the other hand, the sensitivity of 0.48 for this classification scheme in the extracted and re-evaluated patient group shows that reactivity within the defined groups is not as frequent as suspected if the chemical group model were valid.

\section{Frequency/incidence/risk}

The overall frequency of polyvalent reactions (so called "cross-reactivity") ranges from $0 \%$ to $100 \%$ (mean $53.2 \%$ ) in the literature (8,10-16,20-36) (Table 1). Interestingly, only five $(20 \%)$ papers clearly mention the identified frequency of polyvalent reactions as a percentage $(8,10,13,24,34)$, while the others note the absolute number of patients showing "cross-reactivity".

In general, the observed polyvalent and cross-reactions ranged from $0.0 \%$ to $100 \%$ (Table 1), supporting an individual reaction pattern rather than the influence of chemical structure similarities upon positive test results.

'Cross-reactivity' exists only in two groups as shown in Figure 2. Therefore, literature data was re-analyzed. The frequency of polyvalent reactivity is increased as compared to the frequency of cross-reactivity (Table 1).

\section{Correlation of tested ICMs}

Since no significant correlation was found between the 
number of tested ICMs and positive test results (Figure S1), the results do not support an overall reactivity between all ICMs.

\section{Polyvalent reactivity versus cross-reactivity}

The assumption that all ICMs show cross-reactivity with each other is a propagation of the old, incorrect concept of the alleged "iodine allergy" $(1,5)$. Although most authors deny the existence of "iodine allergy", 20 papers were found that regard "cross-reactivity" as multiple positive test reactions throughout the entire group of ICMs (8,10-15,2024,26,28-31,33-35). The kind of definition influences the resulting data (Table 1 ).

\section{Crossover evaluation}

Frequencies of ICM pairings (culprit contrast medium A and positive reaction to contrast medium $B$ and vice versa) should result in nearly equal values. For example, the frequencies of the following pairings:

* Iobitridol (culprit) AND iopromide (reaction partner);

* Iopromide (culprit) AND iobitridol (reaction partner).

should be identical. Surprisingly, in most instances (70\%) such results did not occur which likewise suggests an individual reaction pattern underlying the obtained frequencies, and not reactions driven by chemical structure similarities of the tested ICMs.

\section{$D P T$}

DPTs are used to verify a positive or a negative IDT result. DPTs are necessary in the diagnosis of drug HSRs when skin reaction tests are considered insensitive (37). In the extracted patient group, 200 DPTs were reported $(8,10,11,15,16,20-22,26-29,31,36)$. Most provocations were negative, and only a small proportion were false positive. This means that testing physicians/allergists generally chose the correct (i.e., tolerated) ICMs for the challenge testing. Since the ICM-grouping presented herein (Figure 2) was unknown to them, this decision-making process was not biased. A sensitivity of 0.34 and a specificity of 0.91 $[\mathrm{P}<0.0001$; OR (95\% CI): 0.18 (0.08-0.40)] was calculated. Consequently, the sensitivity of DPT is lower than the sensitivity of IDTs when cross-reactivity is regarded (0.48), and only slightly decreased when polyvalent reactivity is considered (0.32).

\section{Limitations}

The study has the following limitations. Since we extracted data from the literature, not all published patients could be re-evaluated; data from 279 patients were missing. The general problem of insufficient documentation (38) not only hinders efficient management of patients undergoing radiological routine procedures, but also scientific analyses. Another limitation is the relative low number of reevaluated cases. Therefore, further analyses in greater patient groups are necessary.

Broad ranges of other limitations-influencing the skin test accuracy-do also exist. These are, the loss of sensitivity of skin tests over time, including the lack of documenting the diagnostic delay between reaction and skin test, the lack of uniform test protocols (most use 1:10 dilution, but some use undiluted ICM which may improve sensitivity but also perhaps increase false positive, irritative reactions), the lack of standardized test panels, the uncertainty of the clinical relevance of positive skin tests, and the missing differentiation between immediate and nonimmediate HSRs. In many cases, the culprit ICM was unknown; therefore, we excluded a great number of published cases.

\section{Conclusions}

Taken together, the herein provided data show that it is necessary to define ICM groups as the basis for potential cross-reactivity. Without definition or limitation to a group of potential reaction partners, all available ICMs are included, and this implicates that "cross-reactivity" would only replace the old term "iodine allergy" without changing underlying facts or practice.

Given the herein obtained results (e.g., the incidence of "cross-reactivity" ranging from $0 \%$ to $100 \%$ ), it seems likely that an individual reaction pattern plays a major role by influencing the frequencies of multiple positive test reactions rather than similarities of the chemical ICMstructure, and thereby, so-called cross-reactivity.

\section{Acknowledgments}

The authors would like to thank Alan G. Haynes for critically reading the manuscript and statistic support as well as Gerd Böhm for his helpful advice concerning the 
chemical structures of the iodinated contrast media. The authors would also like to thank all colleagues who answered our e-mails, namely Olivier Clement, Axel Trautmann, Brigitte Milpied-Homsi, and Esther Moreno.

Funding: None.

\section{Footnote}

Conflicts of Interest: All authors have completed the ICMJE uniform disclosure form (available at http://dx.doi. org/10.21037/qims-20-1325). IBB reports that the institute receives financial support for congress travelling from Bayer. The other authors have no conflicts of interest to declare.

Ethical Statement: The authors are accountable for all aspects of the work in ensuring that questions related to the accuracy or integrity of any part of the work are appropriately investigated and resolved.

Open Access Statement: This is an Open Access article distributed in accordance with the Creative Commons Attribution-NonCommercial-NoDerivs 4.0 International License (CC BY-NC-ND 4.0), which permits the noncommercial replication and distribution of the article with the strict proviso that no changes or edits are made and the original work is properly cited (including links to both the formal publication through the relevant DOI and the license). See: https://creativecommons.org/licenses/by-nc$\mathrm{nd} / 4.0 \%$.

\section{References}

1. Böhm I, Nairz K, Morelli JN, Keller PS, Heverhagen JT. Iodinated Contrast Media and the Alleged "Iodine Allergy": An Inexact Diagnosis Leading to Inferior Radiologic Management and Adverse Drug Reactions. Rofo 2017;189:326-32.

2. Sohn KH, Kim GW, Lee SY, Kim HS, Cho SH, Han JK, Kang HR. Immediate and delayed hypersensitivity after intra-arterial injection of iodinated contrast media: a prospective study in patients with coronary angiography. Eur Radiol 2019;29:5314-21.

3. Rosado Ingelmo A, Dona Diaz I, Cabanas Moreno R, Moya Quesada MC, Garcia-Aviles C, Garcia Nunez I, Martinez Tadeo JI, Mielgo Ballesteros R, OrtegaRodriguez N, Padial Vilchez MA, Sanchez-Morillas L, Vila Albelda C, Moreno Rodilla E, Torres Jaen MJ. Clinical
Practice Guidelines for Diagnosis and Management of Hypersensitivity Reactions to Contrast Media. J Investig Allergol Clin Immunol 2016;26:144-55.

4. Abe S, Fukuda H, Tobe K, Ibukuro K. Protective effect against repeat adverse reactions to iodinated contrast medium: Premedication vs. changing the contrast medium. Eur Radiol 2016;26:2148-54.

5. Böhm I, Morelli J, Nairz K, Silva Hasembank Keller P, Heverhagen JT. Myths and misconceptions concerning contrast media-induced anaphylaxis: a narrative review. Postgrad Med 2017;129:259-66.

6. López-Matas MA, de Larramendi CH, Moya R, SánchezGuerrero I, Ferrer A, Huertas AJ, Flores I, Navarro LA, García-Abujeta JL, Vicario S, Andreu C, Peña M, Carnés $\mathrm{J}$. In vivo diagnosis with purified tropomyosin in mite and shellfish allergic patients. Ann Allergy Asthma Immunol 2016;116:538-43.

7. Moreno Escobosa MC, Cruz Granados S. Paramagnetic Contrast Media: Hypersensitivity and Cross-Reactivity. J Investig Allergol Clin Immunol 2018;28:60-2.

8. Morales-Cabeza C, Roa-Medellin D, Torrado I, De Barrio M, Fernandez-Alvarez C, Montes-Acenero JF, De La Riva I, Prieto-Garcia A. Immediate reactions to iodinated contrast media. Ann Allergy Asthma Immunol 2017;119:553-7.

9. Fok JS, Smith WB. Hypersensitivity reactions to gadolinium-based contrast agents. Curr Opin Allergy Clin Immunol 2017;17:241-6.

10. Lerondeau B, Trechot P, Waton J, Poreaux C, Luc A, Schmutz JL, Paris C, Barbaud A. Analysis of cross-reactivity among radiocontrast media in 97 hypersensitivity reactions. J Allergy Clin Immunol 2016;137:633-5.e4.

11. Vernassiere C, Trechot P, Commun N, Schmutz JL, Barbaud A. Low negative predictive value of skin tests in investigating delayed reactions to radio-contrast media. Contact Dermatitis 2004;50:359-66.

12. Torres MJ, Gomez F, Dona I, Rosado A, Mayorga C, Garcia I, Blanca-Lopez N, Canto G, Blanca M. Diagnostic evaluation of patients with nonimmediate cutaneous hypersensitivity reactions to iodinated contrast media. Allergy 2012;67:929-35.

13. Schrijvers R, Breynaert C, Ahmedali Y, Bourrain JL, Demoly P, Chiriac AM. Skin Testing for Suspected Iodinated Contrast Media Hypersensitivity. J Allergy Clin Immunol Pract 2018;6:1246-54.

14. Brockow K, Romano A, Aberer W, Bircher AJ, Barbaud A, Bonadonna P, Faria E, Kanny G, Lerch M, 
Pichler WJ, Ring J, Rodrigues Cernadas J, Tomaz E, Demoly P, Christiansen C. Skin testing in patients with hypersensitivity reactions to iodinated contrast media - a European multicenter study. Allergy 2009;64:234-41.

15. Hasdenteufel F, Waton J, Cordebar V, Studer M, Collignon O, Luyasu S, Beaudouin E, Renaudin JM, Morisset M, Kanny G, Barbaud A. Delayed hypersensitivity reactions caused by iodixanol: an assessment of cross-reactivity in 22 patients. J Allergy Clin Immunol 2011;128:1356-7.

16. Seitz CS, Pfeuffer P, Raith P, Brocker EB, Trautmann A. Radiocontrast media-associated exanthema: identification of cross-reactivity and tolerability by allergologic testing. Eur J Radiol 2009;72:167-71.

17. Christiansen C. Late-onset allergy-like reactions to $\mathrm{X}$-ray contrast media. Curr Opin Allergy Clin Immunol 2002;2:333-9.

18. Schönmann C, Brockow K. Adverse reactions during procedures: Hypersensitivity to contrast agents and dyes. Ann Allergy Asthma Immunol 2020;124:156-64.

19. Schmid AA, Böhm IB. Cross-reactivity and polyvalent reactivity in patients with iodinated contrast medium allergy: how to use the terms correctly. Int Arch Allergy Immunol 2021:1-3.

20. Kim SR, Park KH, Hong YJ, Oh YT, Park JW, Lee JH. Intradermal Testing With Radiocontrast Media to Prevent Recurrent Adverse Reactions. AJR Am J Roentgenol 2019;213:1187-93.

21. Kwon OY, Lee JH, Park SY, Seo B, Won HK, Kang Y, An J, Kwon HS, Song WJ, Cho YS, Moon HB, Kim TB. Novel Strategy for the Prevention of Recurrent Hypersensitivity Reactions to Radiocontrast Media Based on Skin Testing. J Allergy Clin Immunol Pract 2019;7:2707-13.

22. Trautmann A, Brockow K, Behle V, Stoevesandt J. Radiocontrast Media Hypersensitivity: Skin Testing Differentiates Allergy From Nonallergic Reactions and Identifies a Safe Alternative as Proven by Intravenous Provocation. J Allergy Clin Immunol Pract 2019;7:2218-24.

23. Gracia-Bara MT, Moreno E, Laffond E, Munoz-Bellido F, Lazaro M, Macias E, de Arriba S, Campanon V, Sobrino M, Davila I. Tolerability of iobitridol in patients with nonimmediate hypersensitivity reactions to iodinated contrast media. Allergy 2019;74:195-7.

24. Clement O, Dewachter P, Mouton-Faivre C, Nevoret C, Guilloux L, Bloch Morot E, et al. Immediate Hypersensitivity to Contrast Agents: The French 5-year CIRTACI Study. EClinicalMedicine 2018;1:51-61.

25. Corbaux C, Seneschal J, Taieb A, Cornelis F, Martinet J, Milpied B. Delayed cutaneous hypersensitivity reactions to iodinated contrast media. Eur J Dermatol 2017;27:190-1.

26. Ahn YH, Koh YI, Kim JH, Ban GY, Lee YK, Hong GN, Jin UR, Choi BJ, Shin YS, Park HS, Ye YM. The Potential Utility of Iodinated Contrast Media (ICM) Skin Testing in Patients with ICM Hypersensitivity. J Korean Med Sci 2015;30:245-51.

27. Grandvuillemin A, Ripert C, Sgro C, Collet E. Iodinated contrast media-induced acute generalized exanthematous pustulosis confirmed by delayed skin tests. J Allergy Clin Immunol Pract 2014;2:805-6.

28. Bircher AJ, Brockow K, Grosber M, Hofmeier KS. Late elicitation of maculopapular exanthemas to iodinated contrast media after first exposure. Ann Allergy Asthma Immunol 2013;111:576-7.

29. Prieto-García A, Tomas M, Pineda R, Tornero P, Herrero T, Fuentes V, Zapatero L, de Barrio M. Skin test-positive immediate hypersensitivity reaction to iodinated contrast media: the role of controlled challenge testing. J Investig Allergol Clin Immunol 2013;23:183-9.

30. Dewachter P, Laroche D, Mouton-Faivre C, Bloch-Morot E, Cercueil J-P, Metge L, Carette M-F, Vergnaud M-C, Clément O. Immediate reactions following iodinated contrast media injection: A study of 38 cases. Eur J Radiol 2011;77:495-501.

31. Torres MJ, Mayorga C, Cornejo-Garcia JA, Lopez S, Chaves P, Rondon C, Fernandez T, Blanca M. Monitoring non-immediate allergic reactions to iodine contrast media. Clin Exp Immunol 2008;152:233-8.

32. Trcka J, Schmidt C, Seitz CS, Brocker EB, Gross GE, Trautmann A. Anaphylaxis to iodinated contrast material: nonallergic hypersensitivity or IgE-mediated allergy? AJR Am J Roentgenol 2008;190:666-70.

33. Kvedariene V, Martins P, Rouanet L, Demoly P. Diagnosis of iodinated contrast media hypersensitivity: results of a 6-year period. Clin Exp Allergy 2006;36:1072-7.

34. Kanny G, Pichler W, Morisset M, Franck P, Marie B, Kohler C, Renaudin JM, Beaudouin E, Laudy JS, Moneret-Vautrin DA. T cell-mediated reactions to iodinated contrast media: evaluation by skin and lymphocyte activation tests. J Allergy Clin Immunol 2005;115:179-85.

35. Dewachter P, Mouton-Faivre C, Felden F. Allergy and contrast media. Allergy 2001;56:250-1.

36. Salas M, Gomez F, Fernandez TD, Dona I, Aranda A, Ariza A, Blanca-Lopez N, Mayorga C, Blanca M, Torres MJ. Diagnosis of immediate hypersensitivity reactions to radiocontrast media. Allergy 2013;68:1203-6. 
37. Rerkpattanapipat T, Chiriac A-M, Demoly P. Drug provocation tests in hypersensitivity drug reactions. Curr Opin Allergy Clin Immunol 2011;11:299-304.

38. Böhm IB, van der Molen AJ. Recommendations for

Cite this article as: Schmid AA, Morelli JN, Hungerbühler MN, Boehm IB. Cross-reactivity among iodinated contrast agents: should we be concerned? Quant Imaging Med Surg 2021;11(9):4028-4041. doi: 10.21037/qims-20-1325
Standardized Documentation of Contrast MediumInduced Hypersensitivity. J Am Coll Radiol 2020;17:1027-8. 


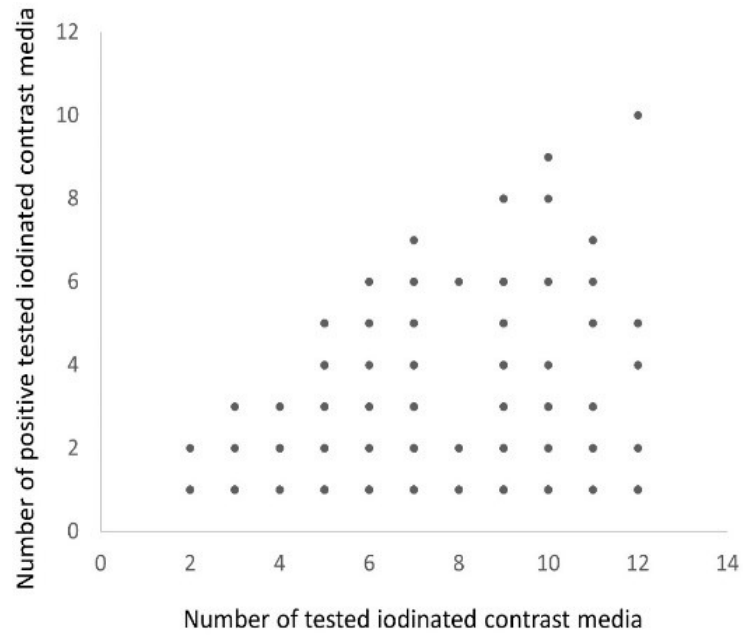

Figure S1 Correlation between number of tested iodinated contrast media and number of positive tested iodinated contrast media in the extracted patient group. Spearman's rho $=0.05357 ; \mathrm{P}>0.05$. 